Reseña

\section{Mercedes Fernández Paradas y Carlos Larrinaga (eds.). Business History in Spain (19th and 20th centuries). Berlín, Peter Lang, 2021, 238 pp. ISBN: 978-3631843857.}

La editorial Peter Lang brinda a los lectores españoles, y espero que aún más a los de fuera de España, un interesante libro sobre nuestra reciente historia empresarial. Su génesis se encuentra en el trabajo que desde hace año vienen desarrollando un grupo de investigadores de Andalucía Oriental con sectores industriales que no han merecido demasiada atención. Me refiero a Juan Manuel Mates, Leonardo Caruana, Mariano Castro y, entre otros, los dos editores de este libro, Mercedes Fernández y Carlos Larrinaga. Quede claro que la ubicación del núcleo de este grupo en parte de una región española es compatible con la participación de historiadores económicos que trabajan en universidades de Madrid, Galicia y Castilla y León. Por otro lado, es considerable la diversidad de enfoques, temas y, también, territorios. En fin, se trata de un grupo heterogéneo al que debemos agradecer el engrosamiento de la bibliografía de nuestra historia empresarial ${ }^{1}$.

Resulta complicado escribir una reseña de este libro. Son muchas empresas, muchos temas y muchas líneas de investigación. No obstante, en un aspecto hay cierta homogeneidad: el tiempo. Nueve de los trece capítulos del libro se refieren al siglo xx. Otro más (sobre las inversiones inglesas en la industria del gas) se refiere al xIx. Y otros tres más se mueven entre los dos siglos. En fin, hay un claro predominio del siglo xx, lo que supone un desplazamiento, diríase modernización, con respecto a las otras monografías. ¿Esto marca una tendencia en el tipo de investigaciones desarrolladas por el grupo? No lo sé. Habrá que esperar a futuras contribuciones.

Como siempre en este grupo, el foco está puesto en sectores empresariales que no son estrellas de la investigación habitual. Pero hay dos excepciones. La primera es doble: el ferrocarril, que es estudiado en dos capítulos, primero como industria de construcción de material móvil (Gregorio Núñez) y luego como servicio de transporte durante la Primera Guerra Mundial (Pedro Pablo Ortúñez y Miguel Muñoz), un tema de indudable interés por razones que sobrepasan el campo de la historia económica empresarial; la otra excepción es la industria del automóvil (Pablo Villa y, de nuevo, Pedro Pablo Ortúñez). Todo sea dicho, esta industria, que ha sido fundamental para la industrialización reciente de España, no siempre ha merecido la atención debida por parte de los historiadores económicos,

\footnotetext{
${ }^{1}$ Al respecto, solo citaré tres monografías: Juan Manuel Mates-Barco (ed.): Empresas y empresarios en España (Pirámide, 2019); María Vázquez, Pedro Pablo Ortúñez y Mariano Castro (eds.): Companies and Entrepreneurs in the History of Spain (Palgrave, 2021); Juan Manuel Mates-Barco y Leonardo Caruana (eds.): Entrepreneurship in Spain. A History (Routledge, 2021).
}

quizás por ser un tema que también ha sido abordado desde la economía aplicada. El trabajo de Villa y Ortúñez, que básicamente es una comparación del sector entre España y Portugal, resulta muy interesante y característico del tipo de investigaciones que hacemos desde la historia. Creo que en los estudios de esta industria hay muchas posibles sinergias y colaboraciones con nuestros colegas de esa área de conocimiento.

Cuatro de los capítulos abordan industrias de red; en concreto, el suministro urbano de agua (Juan Manuel Matés) y el de gas (Nuria Rodríguez, Mercedes Fernández y Alberto Martínez y Jesús Mirás). Y eso está bien porque tales industrias tienen una importancia mucho mayor de la que le suele conceder la bibliografía. Para la mayor parte de la gente corriente, la modernidad no comenzó con la máquina de vapor, sino con el enchufe, el grifo y la espita de gas. En España, y debido al atraso, es una modernidad tardía y complicada. Por eso, echo de menos en este libro un capítulo sobre la otra gran industria de red, la eléctrica. Sin desmerecer ninguno de esos trabajos, el capítulo de Rodríguez sobre las dificultades del suministro (y de más cosas) de la industria del gas de Madrid me ha parecido muy ilustrativo de la política económica del régimen; a fin de cuentas, hablamos de un monopolio.

El libro también incluye capítulos sobre otros negocios poco estudiados en los manuales al uso: la industria hotelera española antes del boom turístico de los sesenta (Carlos Larrinaga); la innovación en la exportación de vinos gaditanos (María Vázquez); la innovación en el sector de los seguros (Leonardo Caruana), y las cooperativas de crédito rural en Andalucía (María José Vargas). En fin, temas infrecuentes que alguien podría calificar incluso como raros, pero, desde luego, no irrelevantes. De hecho, algunos de esos negocios movían cifras considerables. A menudo, su desarrollo en España fue más tardío que en el resto de Europa. Y por eso mismo, pudieron cubrir etapas con más rapidez.

Renglón aparte merecen los capítulos de Jorge Lafuente sobre los perfiles empresariales en los políticos de la Transición, y de Mariano Castro sobre las compañías extranjeras que operaban en España entre 1911 y 1920. Se trata de dos aportaciones que se apartan de las clásicas biografías de empresas que constituyen el grueso de las investigaciones en este campo. También son muy diferentes una de otra, aunque tengan en común el reducido ámbito temporal, lo que permite a sus autores un detalle minucioso de la información.

Business History in Spain es un libro que realiza valiosas aportaciones al campo de la historia económica empresarial de España. Desde la perspectiva de la docencia también es un compendio de materiales útiles para la preparación de esa asignatura. Y desde la perspectiva de la investigación es un jalón más en la lenta construcción de una historiografía necesaria para la elaboración de modelos interpretativos más 
amplios. Una historia empresarial basada en unos pocos sectores representativos difícilmente puede dejarnos satisfechos. Ahora bien, la multiplicación de biografías empresariales en todos los sectores de una economía puede tener un efecto igualmente frustrante: la imposibilidad de reconocer el bosque detrás de tantos árboles. Con libros como este (y los señalados al principio) parece claro que la historiografía empresarial española ha superado el primer problema. Ahora debemos evitar el segundo y buscar explicaciones genéricas que se sostengan en los numerosos materiales que se están poniendo sobre la mesa.

Rafael Barquín Universidad Nacional de Educación a Distancia

https://doi.org/10.33231/j.ihe.2022.01.009 